\title{
The Magic of Layoff Taxes Requires Equilibrium Stability
}

\author{
Frédéric Gavrel*
}

May 2017, revised version

\begin{abstract}
In the same vein as Blanchard and Tirole (2008) First Pass, this note shows that, under the condition for equilibrium stability, the partial implementation of layoff taxes invariably increases firms' profits as well as workers' utilities by lowering payroll taxes. It also proves that requiring stability does not raise any equilibrium existence issue per se: since the budget constraint of unemployment compensation induces multiple equilibria, the condition for stability simply permits the selection of one of these equilibria. These insights could favor the introduction of firing taxes, which in practice would probably be a gradual process.
\end{abstract}

Key words : Layoff taxes, payroll taxes, public policy efficiency.

JEL Classification numbers: H2, J0.

${ }^{*}$ CREM, CNRS (UMR 6211) and University of Caen Normandy, Esplanade de la Paix, 14000 Caen, France; frederic.gavrel@unicaen.fr. I would like to thank Olivier Blanchard for his comments. I am also indebted to Yves Zénou for his helpful suggestions. The usual caveat applies. 


\section{Introduction}

In a well-known paper Blanchard and Tirole (2008) (BT henceforth) show that replacing payroll taxes with layoff taxes to finance unemployment insurance is an efficient policy measure. Acting as a Pigovian tax, layoff taxes make firms internalize the budgetary consequences of their firing behavior. This argument is very convincing and one could ask why this measure has not already been implemented in practice.

More precisely, Blanchard and Tirole prove that in a social optimum the layoff tax should be equal to unemployment benefit, implying that payroll taxes should be set at zero. We here study the comparative statics of firing taxes outside this optimum. Restricting the analysis to a stable equilibrium, we show that increasing the layoff tax necessarily raises firms' profits as well workers' utilities by inducing a decrease in payroll taxes such that the total tax burden declines. Since the introduction of layoff taxes is likely to be gradual in the real world, this complementary insight might help economists convince policy-makers of the merits of firing taxes (or of the experiencerating system).

There is something "magic" in the mechanics of layoff taxes. One could ask how the decrease in payroll taxes can reverse the immediate (negative) effect of the layoff tax increase on profits. In fact, the direct effect of an increase in this tax on expected profits is zero: payroll taxes decrease by the same amount as the firing tax increases. But the firing tax increase also has an indirect negative effect on payroll taxes which results from the decrease in layoffs. The fall in unemployment lowers unemployment costs; hence also the total amount of tax collected (layoff taxes plus payroll taxes). As firms do not take this external effect into account when deciding on their firing strategy, expected profits rise. In addition, the decrease in separation rate enhances workers' expected utilities when unemployment insurance is incomplete. Indeed, with full employment insurance, the layoff tax only acts as a Pigovian tax. But with partial unemployment insurance, the layoff tax also acts a substitute for the ability of firms to commit to a "low" separation rate.

To work, these beautiful mechanics require equilibrium stability. In the absence of this condition the effects of the layoff tax could be reversed. But does such a stable equilibrium exist? In fact, the stability condition does not appear to raise any 
equilibrium existence issue by itself. This is because except in the case where the layoff tax coincides with the unemployment benefit (payroll taxes being reduced to zero), the budget constraint of unemployment insurance generates multiple equilibria: if layoffs are many (few), the financing of unemployment compensation requires a high (low) payroll tax, inducing many (few) workers to be fired. The stability criterion simply permits the selection of one of these multiple equilibria.

Let us briefly position our contribution in the literature, focussing on papers which motivate the introduction of layoff taxes by their welfare effects. Building on Shapiro and Stiglitz (1984), papers by Saint Paul (1995), Fella (2000), and Fath and Fuest (2005) show that the layoff tax allow firms to reduce the efficiency wage (or their monitoring costs) by committing them to a lower separation rate (which raises the utility of non-shirking workers). In general, the motivation for layoff taxes results from unemployment costs. As in BT, layoff taxes make the private cost of layoffs closer to their social cost. In this case, the externality of firms' behavior stems from the balanced budget constraint of unemployment compensation. As shown here, the presence of this budget constraint gives rise to multiple equilibria. As a consequence, the comparative statics of the firing tax are ambiguous. This may explain why this literature either makes use of restrictive assumptions - as in Cahuc and Malherbet (2004) for instance, where the authors are led to assume that total unemployment costs hold constant 1 - or does not provide analytical results, as in L'Haridon (2005) or L'Haridon and Malherbet (2009), who make use of numerical simulation. The present note shows that the condition for equilibrium stability allows one to select an equilibrium where the comparative statics make sense. We believe that this methodological finding might be helpful in the analysis of labor market policy in the presence of a balanced budget constraint.

To summarize, the present note identifies a method of dealing with the budget constraint of unemployment compensation, and applies this method to the comparative statics of the firing tax in $\mathrm{BT}$ to show that a partial implementation of this tax improves welfare. It also specifies the policy implications of the results obtained.

Section 2 presents the model and show that, in conformity with BT, the contri-

\footnotetext{
${ }^{1}$ This means that the benefit rate decreases (increases) as unemployment increases (decreases).
} 
bution of layoff taxes to the financing of unemployment insurance should be equal to one in a social optimum. It also defines a market equilibrium. In section 3 , we show that the budget constraint of the unemployment insurance system generates multiple equilibria, and that one of these equilibria is stable. Section 4 first establishes that increasing layoff taxes raises expected profits, whether unemployment insurance is full or not, and raises expected profits and expected utilities if unemployment insurance is partial. Finally, we specify the policy implications of our results in a comparison with BT, and we discuss their practical relevance and robustness (section 5).

\section{Environment, social optimum, and market equi- librium}

The core of the model borrows from the theory of implicit contracts. Firms are riskneutral, whereas workers are risk-averse. Uncertainty comes from the output, $y$, which is a match-specific random variable whose distribution $G(y)$ is strictly increasing in $[0,1]$. Its density is $g(y)(>0)$. All workers find a firm with which to contract. This contract indicates the wage, $w<1$, that the worker will receive if she is active. If the worker is fired, because her output is too low, she receives the unemployment benefit, $\mu \leq w$.

The wage and the unemployment benefit are exogenous variables. Workers should be incentivized to work, implying that the return to work should be higher than the return to inactivity. Using $\delta \geq 0$ to denote the monetary equivalent of leisure, the wage should satisfy $w \geq \mu+\delta$. This inequality should hold strictly. Nonetheless, we can include the case of full unemployment insurance to achieve a better understanding of the role of the layoff tax. Let $\hat{y}$ be the output cutoff below which workers are fired.

We can distinguish two situations. The first is a normative benchmark. Firms are assumed to be in charge of unemployment insurance $2^{2}$ meaning that they directly pay the unemployed. The second situation describes the real world. In this case, a public agency is in charge of unemployment insurance and firms pay a layoff tax, $f$, which is used in the financing of unemployment benefits, together with the payroll tax, $\tau$.

In the "private" insurance system, a firm will retain the worker if (and only if) the

\footnotetext{
${ }^{2} \mathrm{BT}$ explain why this private system is not viable.
} 
ex post loss $w-y$ is lower than the unemployment benefit, $\mu$. Consequently, in this situation, the "private" cutoff, $\hat{y}$, is determined by $\hat{y}^{p}=w-\mu$. If the output is lower than this cutoff, then the ex post loss is higher than the unemployment benefit and the worker is fired. With full unemployment insurance, this determination of the output cutoff $\hat{y}^{p}=\delta$ is efficient. By contrast, as we will explain later, this determination of the cutoff is not a first best when unemployment insurance is partial.

Let us now turn to the public insurance system. Since $w$ denotes the net wage, the labor cost is $w+\tau$, and the ex post loss becomes $w+\tau-y$. Equalizing this loss to the layoff tax, $f$, determines the "public" cutoff $\hat{y}^{g}$. We obtain $\hat{y}^{g}=w+\tau-f$. The public agency decides on payroll taxes and layoff taxes subject to the balanced budget constraint of the unemployment compensation system. Since there are very many agents, this constraint is written as

$$
G(\hat{y})(\mu-f)=(1-G(\hat{y})) \tau
$$

The question BT ask is: which value of the layoff tax makes market equilibrium coincide with a social optimum? The answer is straightforward. With full unemployment insurance, the firing tax should be set such that firms decide on the optimum cutoff, that is, $\hat{y}^{g}=\hat{y}^{p}=\delta$. We then should have

$$
\mu=-\tau+f
$$

From the budget constraint, we deduce $f=\mu$ and $\tau=0$. In other words, to decentralize the social optimum, the rate of contribution of the layoff tax to the financing of unemployment insurance should be set to $1(=f / \mu)$ if unemployment insurance is full.

The question we ask is complementary. Starting from a situation in which payroll taxes are not zero, what can be said about the efficiency of a gradual introduction of layoff taxes? This question is important as, in the real world, the introduction of layoff taxes is very likely to be partial, at least to begin with.

To address this issue, we need to make the environment more explicit. The expected profits of firms are

$$
E=\int_{\hat{y}}^{1}(y-w-\tau) g(y) d y+G(\hat{y})(-f)
$$


while the expected utility of workers is

$$
V=G(\hat{y}) U(\delta+m u)+(1-G(\hat{y})) U(w)
$$

where $U($.$) is a VNM concave utility function.$

Note that, with full employment insurance $(w=\delta+\mu)$, a change in the cutoff does not affect workers' expected utility. On the other hand, with partial unemployment insurance $(w>\delta+\mu)$, workers' expected utility grows with a decrease in the cutoff.

The budget constraint, which creates a (financial) externality of firms' firing behavior, determines the payroll tax $\tau$ as a function of the couple $(\hat{y}, f)$ :

$$
t(\hat{y}, f)=\frac{G(\hat{y})}{1-G(\hat{y})}(\mu-f)
$$

For $\mu>f$, one can see that the partial derivative of $t($.$) with respect to the cutoff \hat{y}$ is positive, while the derivative with respect to $f$ is negative.

From the determination of the cutoff, it emerges that

Definition 1. An equilibrium can be defined as a value of the cutoff in the interval $[0,1]$ which satisfies

$$
\hat{y}=-f+w+t(\hat{y}, f)
$$

\section{$3 \quad$ Multiple equilibria and stability}

We begin by showing that the budget constraint generates multiple equilibria as long as the layoff tax is lower than the unemployment benefit $(f<\mu)$. Next, we prove that at least one equilibrium is stable, which means that the stability condition does not raise any equilibrium existence issue.

\subsection{Equilibrium existence and multiple equilibria}

In the following, $\Phi(\hat{y}, f)$ denotes the right hand side of the equilibrium equation, that is: 


$$
\Phi(\hat{y}, f)=-f+w+\frac{G(\hat{y})}{1-G(\hat{y})}(\mu-f)
$$

Notice that, for $f<\mu, \Phi(\hat{y}, f)$ is strictly increasing in $\hat{y}$, while strictly decreasing in $f$.

In the comparative statics of the next section, equilibrium existence is needed for all values of the layoff tax. Since $\Phi(\hat{y}, f)$ is decreasing in $f$, this means that the equilibrium equation for $f=0$,

$$
\hat{y}=\Phi(\hat{y}, 0)=w+\frac{G(\hat{y})}{1-G(\hat{y})} \mu
$$

possesses at least a single solution.

This condition, referred to as $(E E)$, is necessary and sufficient for equilibrium existence lato sensu (i.e. for all $f \geq 0$ ).

We now show that if there exists at least one equilibrium for any value of $f$ in the interval $] 0, \mu[$, then there exist at least two equilibria for any value of $f$ in the interval ] $0, \mu[$.

Let $\hat{y}_{1}(f)$ denote the lowest solution for the equilibrium equation for any value of the layoff tax $f$ in $] 0, \mu[$. Notice that, as $\Phi(0, f)>0$, the lowest equilibrium must be strictly positive $\left(\hat{y}_{1}(f)>0\right)$.

For $f=0, \hat{y}_{1}(0)$ may be a tangency point, meaning that $\Phi(\hat{y}, 0)>\hat{y}$ for $0 \leq \hat{y}<$ $\hat{y}_{1}(0), \Phi\left(\hat{y}_{1}, 0\right)=\hat{y}_{1}$, and $\Phi(\hat{y}, 0)>\hat{y}$ for $\hat{y}_{1}(0)<\hat{y}<1$. This implies that for $f=0$, the equilibrium may be unique.

Assuming existence, let us now prove that there exist at least two equilibria for all $f$ such that $\mu>f>0$. The proof is by contradiction. Suppose that the lowest equilibrium $\hat{y}_{1}(f)$ is the single equilibrium for some value of $f>0$. Since $\Phi(\hat{y}, f)$ is strictly decreasing in $f$, it follows that, whether $\hat{y}_{1}(0)$ is a tangency point or not, we should have: $\Phi(\hat{y}, f)>\hat{y}$ for $0 \leq \hat{y}<\hat{y}_{1}(f), \Phi\left(\hat{y}_{1}(f), f\right)=\hat{y}_{1}(f)$, and, in particular, $\Phi(\hat{y}, f)<\hat{y}$ for $\hat{y}_{1}(f)<\hat{y}<1$. On the other hand, we can see that $\Phi(\hat{y}, f)$ goes to $+\infty$ as $\hat{y}$ goes to 1 . This is a contradiction which proves that the existence of at least one equilibrium implies the existence of at least two equilibria for any $f<\mu$. 
Consequently, the existence condition $(E E)$ implies that there are at least two equilibria $\hat{y}_{1}(f)$ and $\hat{y}_{2}(f)$, such that $0<\hat{y}_{1}(f)<\hat{y}_{2}(f)<1$ for all $f$ such that $0<f<\mu$. For $f=\mu$, the cutoff reaches its socially optimal value, $\delta$, with full employment insurance.

The intuition behind this phenomenon of multiple equilibria is simple. If the cutoff is high (low), then unemployment is high (low). Consequently, if the cutoff is high (low), then the payroll tax is high (low), prompting firms to decide on a high (low) cutoff.

\section{$3.2 \quad$ Stability}

The reason why equilibrium stability is questionable is that, through the budget constraint, a change in the cutoff affects the payroll tax $\tau$, which in turn affects the determination of the cutoff. Suppose that, initially, the cutoff is above its equilibrium value, denoted by $\hat{y}^{*}$. In this case firms should be prompted to reduce it. Formally, an equilibrium cutoff, $\hat{y}^{*}$, should satisfy

$$
\hat{y}>(<) \hat{y}^{*} \quad \Leftrightarrow \quad \Phi(\hat{y}, f)-\hat{y}<(>) 0
$$

Consequently, local stability requires that, in the neighborhood of equilibrium, a "small" increase in the cutoff (which increases the payroll tax) reduces the ex post loss $w+t(\hat{y},)-.\hat{y}$. A sufficient condition is that the derivative of the ex post loss (with respect to the cutoff) be negative in equilibrium, or:

Result 1. A sufficient condition for local stability is:

$$
-1+\frac{\partial \Phi(\hat{y}, f)}{\partial \hat{y}}=-1+\frac{\partial t(.)}{\partial \hat{y}}<0
$$

A decrease in the cutoff should not generate such a significant decrease in payroll taxes that ex post profits $\hat{y}-w-\tau$ rise (which would cause another decrease in the cutoff etc...). This stability condition is referred to as $(E S)$.

Does this stability requirement raise an existence issue per se? The answer is in the negative. In fact, we can show that the condition $(E S)$ just allows us to select one of the multiple equilibria. Indeed, consider the lowest equilibrium, $\hat{y}_{1}$, for $f>0$. 
We have $\Phi(\hat{y},)>.(<) \hat{y}$ in the left (right) hand neighborhood of $\hat{y}_{1}$. Consequently, the lowest equilibrium, $\hat{y}_{1}$, is locally stable, implying that

$$
-1+\frac{\partial \Phi(\hat{y}, f)}{\partial \hat{y}} \leq 0 .
$$

The same argument shows that equilibrium $\hat{y}_{2}$ is not stable.

To summarize

Result 2. Under condition (EE), there exists a stable equilibrium cutoff.

It is worth noting that we cannot exclude the existence of multiple stable equilibria. To circumvent this problem, we proceed in the way that general competitive analysis does when the relation between equilibrium and exogenous variables is not univocal. See for instance Grandmont (1985). Namely, for any value of the layoff $\operatorname{tax}, f$, we retain a selection which corresponds to the lowest equilibrium, $\hat{y}_{1}(f) 3^{3}$ "Ordinary" comparative statics require that this implicit function be differentiable. To that end, we make the following assumption on the distribution $G($. Assumption $(G C)$. The ratio $\frac{G(y)}{1-G(y)}$ is strictly convex in the interval $\left.] 0, \hat{y}_{1}(0)\right]$.

This assumption ensures that the lowest equilibrium $\hat{y}_{1}(f)$ is a differentiable (decreasing) function, equal to the social optimum, $\delta$, when the layoff tax coincides with the unemployment benefit, $\mu$ (assuming full unemployment insurance). Figure 1 illustrates this point in the case of a uniform distribution $4_{4}^{4}$

Assumption $(G C)$ also implies that the derivative of $-\hat{y}+\Phi(\hat{y},$.$) is different from$ zero. It follows that the equilibrium, $\hat{y}(f)\left(=\hat{y}_{1}(f)\right)$, satisfies the sufficient condition for local stability, $(E S)$, for $0<f \leq \mu$.

\footnotetext{
${ }^{3}$ It is easy to see that the lowest equilibrium is better for welfare. One could then deduce that policy makers should decide on the appropriate level of the payroll tax. We come back to this issue in section 5 , below.

${ }^{4}$ If this convexity assumption $(G C)$ is not satisfied, $\hat{y}_{1}(f)$ may be discontinuous. Although this possibility does not affect our conclusions (the lowest equilibrium cutoff remains a decreasing function of $f$ ), we exclude such unusual "discontinuous" comparative statics for expositional simplicity.
} 


\section{Comparative statics}

\subsection{Firing taxes reduce layoffs and increase expected profits}

We first study the impact of the firing tax on layoffs. From the equilibrium equation, we deduce the impact of the layoff tax on the (selected) equilibrium value of the cutoff, $\hat{y}(f)=\hat{y}_{1}(f)$. This derivative, denoted by $d \hat{y} / d f$, satisfies

$$
\left[-1+\frac{\partial \Phi(.)}{\partial \hat{y}}\right] \frac{d \hat{y}}{d f}+\frac{\partial \Phi(.)}{\partial f}-1=0
$$

Since the direct impact of $f$ on $\tau$ is negative, we obtain that, for $f<\mu$,

Result 3. Under the condition for equilibrium stability, an increase in the firing tax lowers the equilibrium cutoff.

Restricting the analysis to a stable equilibrium generates meaningful results about the change in the cutoff: an increase in the layoff tax leads firms to retain a worker whose output is lower (inducing a higher ex post loss), implying that the cutoff decreases.

Let us now prove that expected profits are increased. The expected profits, E, are a function of $(\hat{y}, \tau, f)$ :

$$
E=e(\hat{y}, \tau, f)
$$

As the cutoff is a private optimum, the impact of $f$ on the equilibrium value of expected profits, denoted by $d E / d f$, reduces to

$$
\frac{d E}{d f}=\frac{\partial e}{\partial \tau} \frac{d \tau}{d f}+\frac{\partial e}{\partial f}
$$

with $d \tau / d f$ being the derivative of the equilibrium value of $\tau$ with respect to $f$.

It follows that

$$
\frac{d E}{d f}=-(1-G(\hat{y})) \frac{d \tau}{d f}-G(\hat{y}) .
$$

On the other hand, we have 


$$
\frac{d \tau}{d f}=\frac{\partial t(.)}{\partial \hat{y}} \frac{d \hat{y}}{d f}+\frac{\partial t(.)}{\partial f} .
$$

Substitution of $d \tau$ into $d E$ yields

$$
\frac{d E}{d f}=-(1-G(\hat{y}))\left[\frac{\partial t(.)}{\partial \hat{y}} \frac{d \hat{y}}{d f}-\frac{G(\hat{y})}{1-G(\hat{y})}\right]-G(\hat{y}) .
$$

That is

$$
\frac{d E}{d f}=-(1-G(\hat{y})) \frac{\partial t(.)}{\partial \hat{y}} \frac{d \hat{y}}{d f}>0 .
$$

Hence we have proved that, for $f<\mu$ :

Result 4. Under the stability condition, increasing the layoff tax raises firms' expected profits.

This result might sound surprising. There is something "magic" in the incidence of layoff taxes. In fact, the intuition is simple. As the cutoff is a private optimum, its (induced) decrease does not affect firms' profits directly, meaning that to understand the underlying mechanism, one should focus on the effect on the total amount of taxes that firms pay, that is

$$
T(\hat{y}, f)=G(\hat{y}) f+(1-G(\hat{y})) t(\hat{y}, f)
$$

The increase $(d f>0)$ in the firing tax tends to reduce the expected profits by raising the expected firing taxes $(G(\hat{y}) d f)$ that firms actually pay. But, holding the cutoff constant, the direct decrease in expected payroll taxes,

$$
(1-G(\hat{y})) \frac{\partial t(.)}{\partial f} d f=-G(\hat{y}) d f
$$

neutralizes the previous (direct) effect, implying that $\partial T(.) / \partial f=0$. But the firing tax also exerts an indirect negative effect through the fall in the cutoff. The fall in the cutoff lowers the costs of the unemployment compensation agency and this gives rise to an indirect decrease in taxes: 


$$
\frac{\partial T(.)}{\partial \hat{y}} d \hat{y}=g(\hat{y})(f-\tau) d \hat{y}+(1-G(\hat{y})) \frac{\partial t(.)}{\partial \hat{y}} d \hat{y}
$$

or

$$
\frac{\partial T(.)}{\partial \hat{y}} d \hat{y}=g(\hat{y}) \mu d \hat{y}<0
$$

When deciding on their cutoff, firms take into account the change in the taxes that they must pay for a given level of unemployment costs. Consequently, in absolute value, the "perceived" part of the decrease in total taxes, $-(f-\tau) d G(\hat{y})$, is lower than the "true" decrease, $-\mu d G(\hat{y})$. In other words, part of the decrease in total unemployment benefits yields an indirect decrease in payroll taxes that firms do not take into account in the setting of the cutoff. This "unperceived" decrease in taxes raises the expected profits (see the expression for $d E$, above).

As long as $f<\mu$, hence, as long as $\tau>0$, the layoff tax makes firms partially internalize the consequences of their firing behavior on unemployment costs. Consequently, increasing the layoff tax raises expected profits. When $f$ becomes equal to $\mu$, the "perceived" effect of the cutoff coincides with the true effect, meaning that the indirect impact on payroll taxes is reduced to zero.

Notice that this result can be easily transposed to the case where free-entry sets the wage, as in BT. In this case, expected profits (gross of the entry cost) holding constant, the layoff tax will generate a (net) wage $(w)$ increase such that workers benefit from the entire decrease in the total amount of collected taxes (firing taxes plus payroll taxes) which results from the fall in unemployment costs.

Following the same line of reasoning, Gavrel and Lebon (2008) show that firing taxes reduce unemployment by lowering taxes in an a dynamic model similar to Mortensen and Pissarides (1994) $!^{5}$

\footnotetext{
${ }^{5}$ Gavrel and Lebon (2008) prove that equilibrium stability ensures that results are meaningful, but they do not address the issue of the existence of a stable equilibrium. They simply provide a numerical illustration.
} 


\subsection{Unemployment insurance and the effect on expected util- ities}

With perfect unemployment insurance $(w=\delta+\mu)$, the decrease in the cutoff, which lowers the separation rate, has no incidence on workers' expected utilities. They perceive the same income whatever their situation may be.

By contrast, if unemployment insurance is partial $(w>\delta+\mu)$, then an increase of the layoff $\operatorname{tax}(f<\mu)$ raises workers' expected utilities by lowering the firing rate.

To summarize, for $f<\mu$,

Proposition 1. Under the condition for equilibrium stability, increasing the layoff tax -i) increases expected profits and leaves expected utilities unchanged if unemployment insurance is full-ii) increases expected profits as well as expected utilities if unemployment insurance is partial.

If workers receive less when unemployed, firms should offer an adapted contract, according to which they would retain their worker even if the ex post loss is higher than the layoff tax. But this behavior is dubious, since it implies that firms would be able to commit to a cutoff which is too low ex post.

This means that in this case of partial insurance the layoff tax in fact plays two roles: the role of a Pigovian tax and the role of a substitute for firms' ability to commit.6

Furthermore, we can show that, due to this second role, the socially optimal value of the layoff tax becomes higher than the unemployment benefit, $\mu$. Suppose that the surplus of resources, $f-\mu(>0)$, is dedicated to the funding of a subsidy to firms, meaning that the payroll tax becomes negative. With $f-\mu>0, \Phi(\hat{y}, f)$ is decreasing in $\hat{y}$, implying that the comparative statics are much easier. As the unique equilibrium is stable, a small increase in the layoff tax lowers the cutoff and increases workers' expected utilities. On the other hand, holding the net wage constant, the impact on expected profits becomes negative. The intuition is that the decrease in the cutoff reduces the subsidy to firms $(-\tau)$. However, for $f=\mu$, the decrease in

\footnotetext{
${ }^{6}$ This point, which is not explicitly stated in BT, is interesting as it means that a layoff tax can be used as a substitute for firms' capacity to commit, even in the absence of any efficiency wage consideration (as in the literature based on Shapiro and Stiglitz (1984), see the introduction).
} 
profits is a second order effect (the first derivative of $E$ with respect to $f$ is zero, see above). Consequently, if this decrease in the subsidy is compensated by a ("very small") decrease in the wage $(w)$, the impact on workers' expected utility remains positive. Insofar as the decrease in the net wage keep expected profits constant, this means that the layoff tax should be higher than unemployment benefits when unemployment insurance is partial. This is what occurs when free-entry sets the wage as in BT.

\subsection{An example}

To make the analysis easier to grasp, we consider the case in which the distribution of the output is uniform: $G(y)=y$. An equilibrium is a solution to

$$
\hat{y}=-f+w+t(\hat{y}, f)=-f+w+\frac{\hat{y}}{1-\hat{y}}(\mu-f) .
$$

Assuming equilibrium existence, that is: $D \equiv(1-w+\mu)^{2}-4(\mu-f)>0$, and noting that $D^{1 / 2}<1+w-\mu$, we obtain two equilibria $0<\hat{y}_{1}<\hat{y}_{2}<1$ for any $f$ in $] 0, \mu[$ :

$$
\hat{y}_{1(2)}=\frac{1+w-\mu-(+) D^{1 / 2}}{2} .
$$

Figure 1 illustrates the determination of an equilibrium as well as the comparative statics of the firing tax. The convex curve $(R H)$ depicts the right hand of the equilibrium equation: $\Phi(\hat{y}, f)=-f+w+\frac{\hat{y}}{1-\hat{y}}(\mu-f)$. In $\hat{y}_{1}$, the slope of $(R H)$ is lower than one. This means that $-1+\partial t\left(\hat{y}_{1},.\right) / \partial \hat{y}<0$, implying that the equilibrium $\hat{y}_{1}$ actually is stable. On the contrary, the slope of $(R H)$ curve is higher than one in the equilibrium $\hat{y}_{2}$, meaning that this equilibrium is not stable.

This example clearly shows why the condition for stability per se does not raise any equilibrium existence issue. It only enables us to select a single equilibrium.

In response to an increase in the firing tax, the $(R H)$ curve shifts downwards. Figure 1 shows that the stable equilibrium cutoff $\hat{y}_{1}$ is reduced, whereas the unstable one rises. Which does not make sense. As usual, the stability of equilibrium clearly excludes counterintuitive results. 
Figure 1: Uniform distribution: $G(y)=y$.

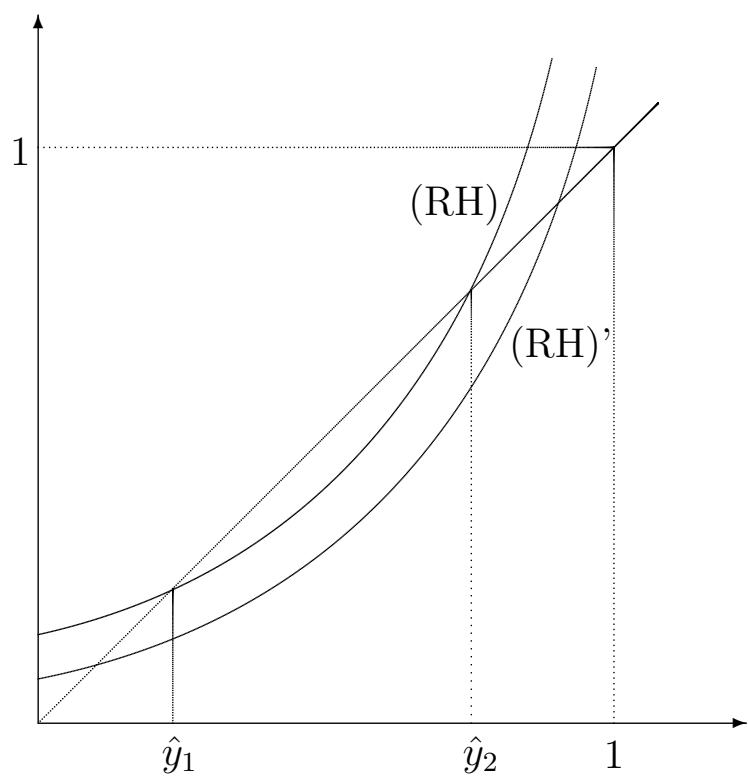

\section{Policy implications}

It is now time to draw out the policy implications of our analysis. To do so, we compare our results with BT and show that they are complementary. For the optimum layoff tax we reach the same conclusion as BT. Like BT, we have proved that, with full unemployment insurance, equalizing the layoff tax with the unemployment benefit makes market equilibrium coincide with a social optimum. We believe however that the comparative statics of the firing tax make this result more intuitive. Indeed, since an increase in the layoff tax is Pareto-improving as long as this tax is lower than the unemployment benefit $(f<\mu)$, we can deduce that the socially optimum tax coincides with unemployment benefits.

As BT put it, the contribution rate of layoff taxes to the financing of unemployment benefits should be equal to one. This is of course an interesting result. Nonetheless, for practical reasons, one also needs to know how the layoff tax affects the budget constraint, as well as the situation of workers and firms outside this social optimum. Policy-makers are indeed very unlikely to implement a "shock therapy" in which payroll taxes would be entirely and suddenly replaced with layoff taxes. The BT policy rule is appealing, and it should be seen as a benchmark. However, 
it is difficult to make this rule operational. For instance, how should we compute the unemployment benefit, $\mu$ ? From our analysis, we can deduce that a gradual introduction of layoff taxes would improve the situation of all individuals by lowering the total amount of taxes collected (layoff taxes plus payroll taxes). This insight is welcome, since policy makers might like to test the merits of the layoff tax through its partial introduction.

Since, for a given value, $f$, of the layoff tax, the lowest equilibrium, $\hat{y}_{1}(f)$, is better for welfare than other (higher) equilibria 7 , one could argue that policy makers should set the payroll tax to the corresponding level, called $\tau_{1}(f)$, that is

$$
\tau_{1}(f)=\frac{G\left(\hat{y}_{1}(f)\right)}{1-G\left(\hat{y}_{1}(f)\right)}(\mu-f) .
$$

This is what is usually assumed in the presence of multiple equilibria that are Pareto-ranked, as here. From our (practical) perspective, this argument does not seem very convincing. Tax authorities are very unlikely to know the optimum payroll tax, $\tau_{1}(f)$, and the same holds for economists. In the real world, they would probably try some value for the layoff tax and see how the budget constraint evolves. If the funds held by the unemployment insurance agency then become excessive, tax authorities would reduce the payroll tax, and they would then see again what happens, etc... One can check whether this kind of tatonnement process converges to one of the stable equilibria (of the cutoff) $]^{8}$ Consequently, what we assume here (implicitly, so far) is that the initial payroll tax is sufficiently close to the optimum, $\tau_{1}(f)$, to make the tatonnement process converge to the lowest equilibrium, $\hat{y}_{1}(f)$. We believe that this assumption sounds more reasonable from a practical point of view.

Our study was restricted to an exogenous wage. There are two reasons for this. First, the theory of wages is not consensual. In that respect, the assumption that firms' competition for workers make expected profits coincide with entry costs is questionable. Assuming that the labor market is competitive, this situation dictates that the number of firms is higher than the number of workers. If not, as a consequence of workers' competition for jobs, the wage would be determined by the utility of an ex

\footnotetext{
${ }^{7}$ Proof is obvious. For a given level of the layoff tax, payroll taxes are lower.

${ }^{8}$ This extends to the case in which the adjustment of the cutoff is not instantaneous.
} 
ante (hence, ex post) unemployed worker ${ }^{9}$. Secondly, what really matters is the way in which the decrease in the total amount of collected taxes is distributed between firms and wages. We assumed above that only firms benefit from the decrease in taxes, whereas BT instead assume that workers are the sole beneficiaries. We can deduce that results are very likely to hold true in the intermediate case, where the two parties benefit from the decrease in taxes.

What can be said about unemployment? This static model does not account for all the effects of layoff taxes on unemployment. In fact, all workers are matched with a firm ex ante, implying that unemployment entirely comes from firms' firing behavior. Hence the layoff tax reduces ex post unemployment. A simple way of accounting for ex ante unemployment (some workers are not matched with a firm) would be to introduce search frictions. One can easily guess how layoff taxes would affect unemployment in such a search-matching structure. The decrease in the labor costs (net wage plus payroll taxes) which we emphasized would stimulate job creation, leading then to a decrease in unemployment. The decrease in entries into unemployment would be accompanied by an increase in the outflow 10 . As a consequence of the unemployment decrease, one can predict a wage increase (whether wages are bargained or posted). In sum, the increase in expected profits would raise labor demand.

Insofar as we do not seek to quantify the effects of layoff taxes, we believe that a more "realistic" model is not needed. In our opinion, the main empirical limitation to our analysis is that some (small) firms are not risk-neutral. One could indeed point out that firms' reluctance to assume risk is precisely the reason why a public agency is in charge of unemployment insurance. The significance of this objection is not so obvious as one might imagine, however. If firms are risk-averse, the (socially) optimal value of the layoff tax will be lower than unemployment benefits, but this value is likely to remain positive. Overall, in countries where legal employment protection (like France) is already present, the costly administrative procedures that this induces (which are a dead-weight loss) could be replaced with firing taxes (which can be used in the financing of unemployment compensation) 11

\footnotetext{
${ }^{9}$ Notice that, in this case, the entry cost would be lower than expected profits.

${ }^{10}$ Formally, the validity of this intuition is very likely to depend on equilibrium stability, not only in terms of the cutoff but also in terms of job creation. See Gavrel and Lebon (2008).

${ }^{11}$ This important point is made by BT and Gavrel and Lebon (2008), independently.
} 


\section{Conclusion}

As a complement to Blanchard and Tirole (2008), our contribution showed that substituting payroll taxes for layoff taxes is desirable, even if this substitution is only partial. This expressive result might impel policy-makers to introduce layoff taxes in the real world. We also provided a method of dealing with comparative statics when the budget constraint of unemployment compensation gives rise to multiple equilibria.

\section{References}

Blanchard, O.J., Tirole, J., 2008. The Joint Design of Unemployment Insurance and Employment Protection: A First Pass, Journal of the European Economic Association, 6(1), 45-77.

Cahuc, P., Malherbet, F., 2004. Unemployment Compensation Finance and Labor Market Rigidity, Journal of Public Economics, 88(3-4), 481-501.

Fath, J., Fuest, C., 2005. Experience Rating versus Employment Protection Laws in a Model where Firms Monitor Workers, Scandinavian Journal of Economics, 107, 299-313.

Fella, G., 2000. Efficiency Wage and Efficient Redundancy Pay, European Economic Review, 44(8), 1473-1490.

Gavrel, F., Lebon, I., 2008. Firing Taxes, Payroll Taxes, and Unemployment, Annals of economics and Statistics, 89, 121-129.

Grandmont, J.M., 1985. Money and Value, Cambridge Books, Cambridge University Press.

L'Haridon, O., 2005. Financement des Politiques du Marché du Travail et Protection de l'Emploi, Economie et Prévision, 168(2), 43-62.

L'Haridon, O., Malherbet, F., 2009. Employment Protection Reform in Search Economies, European Economic Review, 53(3), 255-273.

Mortensen, D.T., Pissarides, C.A., 1994. Job Creation and Job Destruction in the 
Theory of Unemployment, Review of Economic Studies, 61(3), 397-415.

Saint-Paul, G., 1995. Efficiency Wage, Commitment and Hysteresis, Annals of Economics and Statistics, 37/38, 39-53.

Shapiro, C., Stiglitz, J.E, 1984. Equilibrium Unemployment as a Worker Discipline Device, American Economic Review, 74(3), 433-44. 